\title{
Comparison of two bone trephine instruments used for quantitative histomorphometry
}

\author{
R J MOORE, T C DURBRIDGE, A E WOODS, * B VERNON-ROBERTS The Division of \\ Tissue Pathology, Institute of Medical and Veterinary Science, Adelaide, South Australia, and *The School of \\ Pharmacy, South Australian Institute of Technology, Adelaide, South Australia
}

SUMMARY Transilial bone samples were obtained at necropsy using trephine instruments with internal diameters of $2 \mathrm{~mm}$ and $7 \mathrm{~mm}$. Undecalcified histological sections were prepared and two structural histomorphometric variables (percentage of trabecular bone volume and surface density of bone) were estimated by a Quantimet 720 image analyser. The differences between the variables measured from the two adjacent cores were due to differences in biopsy site rather than the size of the sample. The smaller diameter. needle is therefore recommended for use as the biopsy procedure is simpler and tissue sections can be prepared sooner than is the case with the larger needle.

Biopsy of the iliac crest is a common procedure for the detection and management of metabolic bone disorders. When biopsy is followed by quantitative morphometric analysis, the procedure becomes a labour intensive task. As histomorphometric quantitation of bone biopsy specimens continues to be of value in both diagnostic and research fields it is important to determine the smallest sample size which can be used to provide reliable information with confidence. A review of published material shows that there has been a reluctance to use specimens less than 7 or $8 \mathrm{~mm}$ diameter, and there seems to be little justification for this practice. The few quantitative studies performed have reached widely differing conclusions. In some it is reported that the small needles yield specimens which are too short and which also show crushing and distortion artefact..$^{1-3}$ In one study it was stated that a $2 \mathrm{~mm}$ diameter Jamshidi needle produced an adequate specimen for histomorphometric quantitation. ${ }^{4}$ The present study was undertaken to determine the suitability of samples obtained with a small diameter instrument.

\section{Material and methods}

Bone samples were obtained within 24 hours of death from 25 subjects ( 17 men, eight women) with no evidence of malignancy or a condition likely to affect the skeleton. The mean age of the subjects was $61 \cdot 1$ (range 27-82) years. During necropsy, cores of bone were taken from an area $2 \mathrm{~cm}$ behind the anterior aspect of the ilium and $2 \mathrm{~cm}$ below the iliac crest

Accepted for publication 4 August 1988 summit. A $7 \mathrm{~mm}$ diameter specimen was taken first, using the Bordier needle (Edwards Surgical Supplies Ltd, London, England). A second specimen ( $2 \mathrm{~mm}$ diameter) was then taken about $4 \mathrm{~mm}$ to $5 \mathrm{~mm}$ posterior to the first, using the Jamshidi $8 G$ needle (American Pharmaceal Laboratories, Glendale, California, USA). Both cores were taken in the horizontal plane and consisted of the inner and outer cortices with intervening trabecular bone. After fixation in $10 \%$ neutral buffered formalin radiographs were prepared using a Hewlett Packard HP43805N Faxitron $x$-ray cabinet (Hewlett Packard, McMinnville, Oregon, USA), and Kodak Min-R $x$-ray film (Kodak, New York, USA). The samples were embedded undecalcified ${ }^{4}$ and sectioned serially in a longitudinal plane at a thickness of $7 \mu \mathrm{m}$ on a Jung $\mathrm{K}$ motorised microtome (Reichert Jung, Heidelberg, West Germany). Sections were taken at regular intervals through each block, and stained by a combination of the von Kossa silver method and a van Gieson counterstain, permitting discrimination between calcified bone matrix (black), non-calcified osteoid (red), and cellular components (yellow).

Histomorphometric quantitation of the bone sections was performed on a Quantimet 720 image analyser (Cambridge Instruments, Cambridge, UK), linked to a Hewlett Packard HP9000 (Series 200) microcomputer (Hewlett Packard, Fort Collins, Columbia, USA). The overall magnification was $250 \times$ and necessitated three scans to examine the width of the $7 \mathrm{~mm}$ core, but only a single scan of the 2 $\mathrm{mm}$ diameter core. Analysis was restricted to the trabecular region of the core. In addition to scanning the whole of each section from both the $2 \mathrm{~mm}$ and the 7 
$\mathrm{mm}$ diameter cores, the Quantimet also separately scanned the central one third of the $7 \mathrm{~mm}$ wide sections to quantify an area which corresponded to a "hypothetical $2 \mathrm{~mm}$ trephine" taken from the centre of the same anatomical location as the $7 \mathrm{~mm}$ diameter core.

\section{DEFINITION OF VARIABLES}

Percentage of trabecular bone volume (\%TBV): that proportion of the total biopsy specimen volume (including marrow space) which is occupied by trabecular bone (mineralised or osteoid).

Surface density of bone $(M S / U V)\left(\mathrm{mm}^{2} / \mathrm{mm}^{3}\right)$ : the surface area of trabeculae $\left(\mathrm{mm}^{2}\right)$ per unit volume of whole bone tissue $\left(\mathrm{mm}^{3}\right)$, including bone and marrow.

All statistical analyses were performed on a Hewlett Packard HP9000 (Series 200) microcomputer using the General Statistics package, or on a MacIntosh Plus microcomputer using the STATWORKS statistics package. The biopsy specimen lengths were compared using Student's paired $t$ test (two tailed) with significance set at the $95 \%$ confidence interval.

All other comparisons were evaluated using a mixed model (type 111) two way analysis of variance for a two factor experiment. ${ }^{5}$

\section{Results}

Examination of the radiographs showed no evidence of crushing or fracture along the length of the cores. The transilial cores ranged in length from $5 \mathrm{~mm}$ to $23 \mathrm{~mm}$, depending on the thickness of the subject's ilium at the biopsy site. The average length of the $2 \mathrm{~mm}$ diameter Jamshidi cores (10.5 (SD 3.6) $\mathrm{mm}$ ) was not significantly different from the $7 \mathrm{~mm}$ Bordier trephines $(10 \cdot 1(3 \cdot 5) \mathrm{mm})$.

\section{HISTOMOR PHOMETRY}

The histomorphometric estimates of \% TBV and MS/ UV from the two different bone biopsy specimens and the hypothetical $2 \mathrm{~mm}$ diameter biopsy specimen are shown in the table. The results of a two way analysis of variance performed on the data from the adjacent specimens show that there was significant variation

Table Histomorphometric data from transilial bone trephine taken from the left anterior superior iliac spine

\begin{tabular}{|c|c|c|c|c|c|}
\hline \multirow{2}{*}{$\begin{array}{l}\text { Trephine } \\
\text { diameter }\end{array}$} & \multirow[b]{2}{*}{$(n=)$} & \multicolumn{2}{|l|}{$\% T B V$} & \multicolumn{2}{|c|}{$M S / U V$} \\
\hline & & Meant & $(S D)$ & Mean & $(S D)$ \\
\hline $\begin{array}{l}7 \mathrm{~mm} \\
2 \mathrm{~mm} \\
2 \mathrm{~mm}\end{array}$ & $\begin{array}{l}25 \\
25 \\
25\end{array}$ & $\begin{array}{l}18 \cdot 3 \\
17 \cdot 4 \\
17 \cdot 9\end{array}$ & $\begin{array}{l}6 \cdot 0 \\
5 \cdot 2 \\
6 \cdot 5\end{array}$ & $\begin{array}{l}2 \cdot 06 \\
2 \cdot 20 \\
2 \cdot 20\end{array}$ & $\begin{array}{l}0.62 \\
0.69 \\
0.69\end{array}$ \\
\hline
\end{tabular}

*hypothetical $2 \mathrm{~mm}$ trephine.

tThe case mean is the mean of the estimates from replicate slides in each subject. due to "cases"- that is, variation resulting from differences between subjects-(F value for \%TBV $31 \cdot 163 ; 24 \mathrm{df}, \mathrm{p}<0.05$; F value for MS/UV 5.745; $24 \mathrm{df}, \mathrm{p}<0.05)$ and also due to "interaction mechanisms" - that is, variation resulting from the pairing of particular cases with a biopsy method ( $F$ value for \%TBV 11.479; $24 \mathrm{df}, \mathrm{p}<0.05 ; \quad \mathrm{F}$ value for MS/UV 3.686; $24 \mathrm{df}, \mathrm{p}<0.05$ ). This suggests that the variation in morphometric estimates was due either to the natural (biological) variation between the individual cases, or that it was a consequence of the site variation between the two different size biopsy specimens.

The results of a two way analysis of variance comparing the data from the $7 \mathrm{~mm}$ diameter samples with those from the hypothetical $2 \mathrm{~mm}$ samples show that there was significant variation due to "cases" alone (F value for \%TBV 38.097; $24 \mathrm{df}, \mathrm{p}<0.05$; F value for MS/UV 5.748; $24 \mathrm{df}, p<0.05$ ). In this instance the hypothetical $2 \mathrm{~mm}$ biopsy specimen was physically within the $7 \mathrm{~mm}$ biopsy specimen in an attempt to minimise the variation due to biopsy site. While there is again no evidence for any significant influence from the method such as size of specimen, there is also no evidence for any significant interaction mechanisms between the method and the cases.

\section{Discussion}

Quantitative histomorphometry of iliac crest bone continues to be a popular method in diagnostic and research areas. As it is an invasive technique it is important to identify the smallest sample size which can be used with consistency and reliability. The few investigations undertaken have reached differing conclusions. ${ }^{14}$ With this in mind, we investigated whether a $2 \mathrm{~mm}$ diameter bone sample can be used to determine two of the most useful histomorphometrically quantitative variables with the same reliability as a $7 \mathrm{~mm}$ diameter sample. The two variables were chosen because they are common to most of the published studies on bone histomorphometry, and because they can be readily estimated by the Quantimet Image Analyser. The two bone trephines were chosen because they represent the extremes of the commonly used biopsy methods.

The fact that differences were not detected between the core lengths or that no fragmentation artefacts were seen indicates that the smaller needle does not cause any important compression or structural damage to the bone during retrieval of the sample.

A signficant morphometric difference was identified between samples separated by less than $5 \mathrm{~mm}$, but it was not possible to ascertain whether this was due to differences in the diameters of the samples or to differences in the architecture at different sites. For this 
reason, the hypothetical $2 \mathrm{~mm}$ trephine model was used to test the concept that a $2 \mathrm{~mm}$ diameter sample is morphometrically indistinguishable from a $7 \mathrm{~mm}$ diameter sample from the same anatomical site. In this way the biopsy site factor could not influence the estimates. Indeed, when this was tested, the interaction term became insignificant, indicating that biopsy site does contribute significantly to morphometric variation. Although variation in biopsy site is the most likely cause of "interaction" variance, there is theoretically one other source-namely, interaction between method and case. This would arise if the large biopsy, for example, tended to produuce a higher reading than the smaller biopsy for some cases and a lower reading for other cases. Manifestation of this variation cannot be disentangled from site variation, but it seems unlikely to exist, and this is confirmed by the fact that the interaction mean square is not significantly greater than the error mean square in the analysis of variance $(7 \mathrm{~mm} v$ hypothetical $2 \mathrm{~mm})$, showing no site variation and no interaction between method and case. The subjects in this study, although selected to exclude certain diseases known to affect bone state, were otherwise selected randomly, regardless of age or sex, and so significant "case" variation between them is to be expected.

Quite apart from the morphometric findings of this study, there are other considerations which make the small diameter sample a more reasonable proposition than the large diameter sample. Firstly, the Jamshidi biopsy technique is less invasive and therefore likely to be tolerated by the patient.' Importantly, the prepartion time in the laboratory is reduced from $12^{6}$ to three days, which means that diagnostic reports can be issued sooner and treatment can be started or adjusted as required.

While this study has reported results for only two morphometric variables, it is accepted that further work is needed to investigate other variables of bone remodelling, particularly those relating to bone formation and resorption. In particular, relatively large bone samples may be required to quantify precisely rare features such as sites of tunnelling resorption or multinucleate osteoclasts. More common features, however, may be adequately quantified with smaller cores as much of the discrepancy between these and larger cores can be attributed to the depth of core analysed to attain a standard number of fields, and to the differences between transitional and deeper cancellous bone.?

We thank Professor J N Darroch for help with the statistical analysis of the data.

\section{References}

1 Faugere M-C, Malluche HH. Comparison of different bonebiopsy techniques for qualitative and quantitative diagnosis of metabolic bone diseases. J Bone Joint Surg 1983;65A:1314-19.

2 Meunier PJ. Histomorphometry of the skeleton. In: Peck WA, ed, Bone and mineral research annual 1. Amsterdam: Excerpta Medica, 1983:191-4.

3 Vigorita VJ, Anand VS, Einhorn TA. Sampling error in diagnosing hyperparathyroid changes in bone in small needle biopsies. Am J Surg Pathol 1986;10:140-2.

4 Hill BD. A technique for the sectioning of mineralised bone. Aust $J$ Med Technol 1973;4:9-11.

5 Hays WL. Statistics. London: Holt, Reinhart and Wilson, 1970;440.

6 Dunstan CR, Evans RA. Quantitative bone histology. A new method. Pathology 1980;12:255-64.

7 Malluche HH, Meyer W, Sherman D, Massry SG. Quantitative bone histology in 84 normal American subjects. Micromorphometric analysis and evaluation of variance in iliac bone. Calcif Tissue Int 1982;34:449-55.

Requests for reprint requests to: Dr R J Moore, Bone \& Joint Laboratory, Division of Tissue Pathology, Institute of Medical and Veterinary Science, PO Box 14, Rundle Mall, Adelaide, South Australia, 5000. 